\title{
Disentangling longitudinal relations between physical activity, work-related fatigue, and task demands
}

\author{
Juriena D. de Vries ${ }^{1} \mathbb{D} \cdot$ Brigitte J. C. Claessens $^{1} \cdot$ Madelon L. M. van Hooff $^{1}$ • \\ Sabine A. E. Geurts ${ }^{1} \cdot$ Seth N. J. van den Bossche ${ }^{2} \cdot$ Michiel A. J. Kompier $^{1}$
}

Received: 17 July 2014 / Accepted: 22 April 2015 / Published online: 8 May 2015

(C) The Author(s) 2015. This article is published with open access at Springerlink.com

\begin{abstract}
Purpose This longitudinal study examined 'normal', 'reversed', and 'reciprocal' relationships between (1) physical activity and work-related fatigue; and (2) physical activity and task demands. Furthermore, the effects of acrosstime change in meaningful physical activity groups on levels of employees' work-related fatigue and task demands were studied. These groups were based on employees' compliance with the international physical activity norm. Methods Two waves with a one-year time lag of a national representative survey on the quality of work, health, and well-being among Dutch employees were used $(N=2275)$. Longitudinal effects were tested using Structural Equation Modelling. Meaningful physical activity groups were compared using group-by-time analysis of covariance.

Results Support was found for reciprocal relations between physical activity and work-related fatigue. It was found that an increase in physical activity is associated with a decrease in work-related fatigue over time and that an increase in work-related fatigue is associated with a decrease in physical activity over time. No significant longitudinal relations were found between physical activity and task demands. Employees whose compliance with the physical activity norm changed over time showed fairly stable levels of work-related fatigue and task demands.

Conclusions The current findings provide evidence for the potential role of physical activity in the prevention
\end{abstract}

Juriena D. de Vries

j.devries@psych.ru.nl

1 Behavioural Science Institute, Radboud University, P.O. Box 9104, 6500, HE, Nijmegen, The Netherlands

2 Department of Work, Health \& Care, TNO, Leiden, The Netherlands and reduction in work-related fatigue. However, results also indicate that fatigued workers, who would benefit most from physical activity, are less physically active. Our results further indicate that relying on changes in compliance to the physical activity norm may not be the most suitable way to examine changes in work-related fatigue.

Keywords Work-related fatigue $\cdot$ Physical activity $\cdot$ Task demands $\cdot$ Longitudinal research $\cdot$ Physical activity norm

\section{Introduction}

There is a growing body of evidence that physical activity is an effective remedy against mental health problems (Conn 2010; Cooney et al. 2013). As a substantial proportion of mental health problems is work related (estimated at $22 \%$; Eurofound 2012; Niedhammer et al. 2014), it is valuable to examine the potential of physical activity to reduce such problems. Although previous studies do point to negative associations between physical activity and, for example, work-related fatigue (e.g. Bernaards et al. 2006; Carson et al. 2010), job stress (Van Rhenen et al. 2005), and burnout (Gerber et al. 2013; Jonsdottir et al. 2010), insight into the role of physical activity in the prevention and reduction in these types of problems can be advanced in at least three ways.

First, the 'bi-directional' relationships between physical activity and work-related mental health need to be addressed. Existing studies almost exclusively focused on the question how physical activity affects work-related mental health (e.g. Bernaards et al. 2006; Carson et al. 2010; Jonsdottir et al. 2010), and ignored the possibility that employees' work-related mental health status may also influence the amount of physical activity they engage 
in. This is unfortunate, as it may be expected that employees who report high levels of work-related fatigue lack the resources to engage in regular physical activity. In other words, it is likely that work-related mental health and physical activity mutually affect each other.

Secondly, it has been widely established that adverse work characteristics play a key role in the aetiology of work-related mental health problems (e.g. Kompier 2003; De Lange et al. 2003). Therefore, to obtain a complete picture of the potentially beneficial role of physical activity for employee health and well-being, paying attention to their work environment is of vital importance. Although empirical evidence shows that (certain combinations of) work characteristics are related to employees' physical activity level (Fransson et al. 2012; Kouvonen et al. 2013), the directionality of these associations is still not well understood.

Third, previous research on the associations between physical activity, work, and mental health was mainly cross sectional in nature, and the few longitudinal studies that exist did not take into account that for some employees a change in their level of physical activity may have been 'meaningful' (e.g. from considerably high levels to considerably low levels), whereas others report a stable (high or low) level of activity over time. It is therefore valuable to closely examine meaningful subgroups that differ in their initial levels and course of physical activity over time (i.e. 'stability and change paradigm'; De Lange et al. 2002; Van Hooff et al. 2005). This paradigm can provide more insight in what changed levels of physical activity mean for levels of work-related mental health and work characteristics.

In this study, we aim to enhance insight into the association between physical activity and work-related mental health by addressing these three issues. To these purposes, we used a two-wave longitudinal full panel design with a one-year time interval of a survey on the quality of work, health, and well-being among Dutch employees. We focused on work-related fatigue as an indicator of work-related mental health problems, as work-related fatigue is the most commonly reported element of burnout (Maslach et al. 2001) and prevalent among the working population (i.e. estimated at $18 \%$ in Europe; Milczarek et al. 2009). In addition, based on Karasek's (1979) Job-Demands-Control Model, we focused on 'quantitative task demands' as an indicator of work characteristics. Task demands refer to the degree to which work requires employees' effort (Hockey 2013), for instance, working fast and performing a lot of work. Finally, we defined physical activity as an activity that requires (at least moderate intensity) physical effort (WHO 2010).

\section{Physical activity and work-related fatigue}

Although physical activity requires physical energy and physical recovery (Ament and Verkerke 2009), it can also deliver 'mental' energy and reduce feelings of (workrelated) fatigue (e.g. Bültmann et al. 2002; Lindwall et al. 2013). The exact working mechanisms underlying these observed associations are still unclear (Puetz and Herring 2013). Both biological and psychological hypotheses have been proposed. Concerning the former, endorphin or monoamine hypotheses state that physical activity results in changes in certain neurotransmitters (e.g. endorphin) that are associated with feelings of energy, but the evidence is still weak (Dishman and O'Connor 2009). Further, by means of regular physical activity, the body is 'toughened up' and is better able to handle (psychological) stress (Sothman et al. 1996). This results in lower bodily reactions due to (work) stress (i.e. lower stress reactivity; Wipfli and Ramirez 2013) and faster bodily recovery after being exposed to (work) stress (i.e. faster stress recovery; Spalding et al. 2004). Several other biological processes have been proposed as well, see for an overview Dishman et al. (2006).

With regard to psychological hypotheses, it has been proposed that physical activity increases people's self-efficacy (Craft 2005), generates positive feelings about the self (Feuerhahn et al. 2014), and creates a more positive body image (Campbell and Hausenblas 2009). Physical activity may also generate energy by providing people the opportunity to distract themselves from negative stimuli, such as rumination about work (i.e. 'psychological detachment', Sonnentag 2012; distraction hypothesis, Leith 1994), and instead, shift towards more pleasant stimuli (Tian and Smith 2011).

In line with these proposed beneficial effects, cross-sectional studies indeed show negative associations between physical activity and work-related fatigue (Carson et al. 2010; Mollart et al. 2013). The few available longitudinal (Bernaards et al. 2006; Lindwall et al. 2013) and intervention studies (e.g. Gerber et al. 2013; Proper et al. 2003; Tsai et al. 2013; Van Rhenen et al. 2005) show comparable relationships. Also, diary studies indicate that physical activity can decrease work-related fatigue on a daily level (Nägel and Sonnentag 2013; Rook and Zijlstra 2006). Thus, based on previous theory and empirical findings, we hypothesize:

Hypothesis 1a Higher physical activity levels are associated with lower levels of work-related fatigue one year later.

The opposite relationship between physical activity and work-related fatigue may exist as well: employees who experience high levels of work-related fatigue may be less physically active. Generally, fatigue is seen as an adaptive phenomenon: it is a signal to stop a certain task (before damage occurs) and is therefore associated with people having a lower tendency to start or complete tasks, in particular when a task requires a high level of effort (Hockey 
2013). As physical activity is effortful, it can be assumed that work-related fatigue will negatively affect the extent to which employees engage in this type of activity. In support of this assumption, scarce available empirical evidence shows that employees experiencing higher levels of workrelated fatigue reported lower levels of physical activity (Ahola et al. 2012; Gorter et al. 2000). Based on the rationale that fatigue is associated with a tendency to avoid physical activity due to the effort this requires, we propose:

Hypothesis 1b Higher levels of work-related fatigue are associated with lower levels of physical activity one year later.

\section{Physical activity and task demands}

Employees' level of task demands at work may negatively affect the extent to which they engage in physical activity. First, high task demands may deplete personal (e.g. selfregulatory, Nägel and Sonnentag 2013; Sonnentag and Jelden 2009) and other resources (e.g. time, due to commuting or long working hours) that are needed to engage in physical activity. Furthermore, based on the perseverative cognition hypothesis (Brosschot et al. 2006), it can be expected that employees with higher task demands at work stay cognitively preoccupied with work during off-job time, which prolongs their physiological activation after work. It has been found that this inability to cognitively 'switch off' from work is associated with less personal control over leisure time (Cropley and Purvis 2003), making it more difficult to engage in physical activity. Indeed, the scarce available research shows a negative association between task demands and levels of physical activity (Fransson et al. 2012; Kouvonen et al. 2013; Payne et al. 2002). Based on these theoretical notions and empirical findings, we expect:

Hypothesis 2a Higher levels of task demands are associated with lower levels of physical activity one year later.

One could also argue that employees' physical activity level influences perceived task demands at work. An explanation for this association is that physical activity enhances individuals' (physiological, psychological, and cognitive) health, and hence increases employees' ability to handle demands during the workday, as they require less effort (cardiovascular fitness hypothesis, e.g. Colcombe and Kramer 2003). In other words, physical activity may lead to increased (physiological, psychological, and cognitive) capacity to cope with the demands at work. Indeed, research indicates that physical activity can contribute to employees' capacity to perform their assigned tasks (Arvidson et al. 2013). Research has also shown that regular physical activity is associated with mastery experiences and increases in self-efficacy (Craft 2005). Increased self-efficacy may be transferred to the work domain, resulting in employees feeling more competent to meet the task demands at work (Feuerhahn et al. 2014; Rook and Zijlstra 2006). Consequently, they may experience their tasks as less demanding. Thus, based on the idea that physical activity may increase employees' capacity to cope with work demands and therefore causes a shift towards a more positive evaluation of these demands, we hypothesize:

Hypothesis 2b Higher levels of physical activity are associated with lower levels of task demands one year later.

\section{Meaningful subgroups based on physical activity norm}

To get further insight into the role of physical activity in relation to work-related mental health and work characteristics, it is worthy to examine 'meaningful' subgroups that differ in their initial levels and course of physical activity over time (cf. De Lange et al. 2002; Van Hooff et al. 2005). Therefore, in the present study, we examine two groups of employees who differ in their starting points and courses over time regarding their engagement in physical activity. To create these meaningful subgroups, we rely on the international norm for physical activity developed by the World Health Organization (World Health Organization [WHO] 2010), which states that people of 18 years or older should engage in at least $30 \mathrm{~min}$ of moderate-intensity physical activity on at least 5 days a week (in bouts of minimally $10 \mathrm{~min}$ a time) to stay healthy (Hildebrandt et al. 2010). The two groups comprise the following: (1) those employees who do not comply with the physical activity norm at the first time, but do so at the second time (i.e. 'upward' indicating a beneficial change); and (2) those employees who comply with the exercise norm at the first time, but do not at the second time (i.e. 'downward' indicating an unfavourable change). We expected-in accordance with previous hypotheses - that compliance with the physical activity norm is related to lower levels of work-related fatigue and task demands:

Hypothesis 3a Employees in the upward physical activity group (i.e. 'low-high') report a decrease in work-related fatigue and task demands 1 year later.

Hypothesis 3b Employees in the downward physical activity group (i.e. 'high-low') report an increase in workrelated fatigue and task demands 1 year later. 


\section{Methods}

\section{Sample}

This study was based on a two-wave full panel design with a one-year time lag. The participants were part of the TNONetherlands Working Conditions Cohort Study in 2008 and 2009 (NWCCS; Koppes et al. 2010), a survey focused on quality of work, health, and well-being of Dutch employees (self-employed were excluded from the sampling framework). A total of 7909 employees $(76.10 \%$ of the initial approached employees in 2008) filled out the questionnaire in both 2008 and 2009. We selected employees who worked fulltime ( $\geq 36 \mathrm{~h}$ a week), to ensure a sufficient exposure to task demands at work. This restriction reduced our sample size to 3583 employees. Furthermore, we excluded employees who worked in physically demanding jobs, because these jobs generally require 'unhealthy physical activity', such as lifting and pushing, which has already been found to be related to unfavourable health outcomes (e.g. Trinkoff et al. 2001). Hence, we only included employees who answered 'no' to the question 'Do you perform work in which you have to put strength, such as pushing, lifting, pulling, and hauling, or do you use tools and equipment in which you have to put strength?' ( $1=$ yes, regularly, $2=$ yes, sometimes, $3=$ no). This exclusion criterion further reduced our sample size to 2275 employees. Of this final sample $(N=2275$, $28.8 \%$ of the original sample), $75.3 \%$ were male $\left(M_{\text {age }} 45.8\right.$, $\mathrm{SD}=10.0)$ and $24.7 \%$ female $\left(M_{\text {age }}=39.9, \mathrm{SD}=11.4\right)$. This distribution differed from the original sample in which $48.3 \%$ were male $\left(M_{\text {age }} 46.3, \mathrm{SD}=10.9\right)$ and $51.7 \%$ were female $\left(M_{\text {age }} 42.9, \mathrm{SD}=11.2\right)$. Mean working hours of the final sample were $38.4(\mathrm{SD}=3.1)$ and mean working days were $4.9(\mathrm{SD}=0.5)$. The employees of the final sample were mainly well educated $(60.3 \%$ higher professional education), and this differed from the original sample (42.8\% higher professional education). Selected employees primarily worked in the area of business services $(19.3 \%)$, public administration $(17.5 \%)$, industry (14.6\%), and education $(9.9 \%)$. These figures were comparable with those in the original sample, except that much more employees in the original sample worked in a healthcare setting $(23.0 \%)$ compared to the final sample $(8.2 \%)$.

\section{Materials}

Task demands were measured with a four-item scale (e.g. 'Do you have to work fast?'; $1=$ never, 2 = sometimes, 3 = often, 4 = always) that was derived from a Dutch version of the Job Content Questionnaire (JCQ; Houtman 1995; Karasek et al. 1998). The reliability of the scale was high for both waves (Cronbach's $\alpha=0.86$ in 2008 and 0.85 in 2009, respectively).
Physical activity was assessed with the following question: 'On how many days a week are you normally physically active during at least $30 \mathrm{~min}$ a day (only count physical activity that is equally demanding as brisk walking or biking. Activities shorter than $10 \mathrm{~min}$ do not count)—during your work and free time together?' Participants indicated how many days they complied with a minimum of 30 min of physical activity (0-7 days). This item was based on international standards for physical activity (World Health Organization [WHO] 2010), which state that people $\geq 18$ years of age should engage in at least $30 \mathrm{~min}$ of moderate-intensity physical activity minimally 5 days a week (in bouts of minimally $10 \mathrm{~min}$ a time) to stay healthy.

Work-related fatigue was measured with the five-item 'exhaustion'-subscale of the Dutch version of the Maslach Burnout Inventory (Utrechtse Burnout Scale [UBOS] Schaufeli and Van Dierendonck 2000). A typical item is: 'I feel burned out from my work' ( $0=$ never, $6=$ every day $)$. The reliability of the scale was high for both waves (Cronbach's $\alpha=0.87$ in 2008 and 0.88 in 2009, respectively).

Control variables, age, gender, education, working overtime and working irregular hours, measured at T1, were included as control variables. Gender was coded as $1=$ male and $2=$ female. Education was coded as $1=$ low; $2=$ intermediate; $3=$ high professional education. Working overtime was assessed as overtime hours, using the following question: 'On average, how many hours a week do you work overtime?' (paid and unpaid work; include work you execute at home; don't include your commuting time). For working irregular hours, a variable was computed, in which employees who had no irregular work were classified as ' 1 ', and employees who worked at night, in the evening, in the weekend, or had shift work were classified as ' 2 '.

\section{Statistical approach}

Descriptive statistics (means, standard deviations, percentages, and correlations) were calculated in order to study the prevalence of task demands, physical activity, and workrelated fatigue for 2008 (T1) and 2009 (T2). Additionally, it was observed whether compliance with the physical activity norm is related to (high levels of) work-related fatigue and task demands. Next, two steps were taken to test our hypotheses.

\section{Across-time relationships}

To test Hypotheses 1a and 1b, Structural Equation Modelling (SEM) was performed using LISREL version 9.1 (Jöreskog and Sörbom 1993). SEM was used because this technique allowed us to test reciprocal relationships between constructs. To investigate the associations between 
physical activity and work-related fatigue (Hypotheses 1a and $1 \mathrm{~b}$ ), four models were compared to each other. The first model (M1; no causation) included lagged effects from physical activity at $\mathrm{T} 1$ to physical activity at $\mathrm{T} 2$, and from work-related fatigue at $\mathrm{T} 1$ to work-related fatigue at $\mathrm{T} 2$. Age, gender, education, working overtime, and working irregular hours were added as covariates to this model and were modelled to be related to physical activity and workrelated fatigue at $\mathrm{T} 1$. The second model (M2; normal causation) resembled M1, but also included a path from physical activity $\mathrm{T} 1$ to work-related fatigue $\mathrm{T} 2$. The third model (M3; reversed causation) resembled M1, but now included a 'reversed' path from work-related fatigue $\mathrm{T} 1$ to physical activity T2. The fourth model (M4; reciprocal causation) resembled M1 and additionally included the paths of M2 and M3 so that reciprocal relationships between physical activity and work-related fatigue were investigated. The fit of the four models was compared using Chi-square difference tests, the comparative fit index (CFI), the non-normed fit index (NNFI), the adjusted goodness-of-fit index (AGFI), and the root mean square error of approximation (RMSEA) (Bentler and Bonnett 1980). Model fit was considered acceptable if the NNFI, CFI, and the AGFI were $\geq 0.90$ and RMSEA was $\leq 0.08$ (Marsh et al. 2004).

To test Hypotheses $2 \mathrm{a}$ and $2 \mathrm{~b}$ (associations between task demands and physical activity), similar analytical steps were used, meaning that again four models were compared with each other. As we entered variables measured on $\mathrm{T} 1$ as a predictor into the analyses, we controlled for $\mathrm{T} 1-\mathrm{T} 2$ stability effects. As a result, the results of SEM reflect changes between $\mathrm{T} 1$ and $\mathrm{T} 2$ of, respectively, physical activity, task demands, and work-related fatigue.

\section{Subgroup analyses}

We investigated whether changed levels of compliance with international standards of physical activity were related to accompanying changes in levels of task demands and work-related fatigue (Hypothesis 3a and 3b). Therefore, for $\mathrm{T} 1$ and $\mathrm{T} 2$, two groups were created based on employees' physical activity level. If employees were physically active for at least $30 \mathrm{~min}$ a day on $<5$ days a week, they were classified as 'low' (i.e. not meeting the physical activity norm). If employees were physically active at least $30 \mathrm{~min}$ on 5 days or more, they were classified as 'high' (i.e. meeting the physical activity norm).

To test the hypotheses, employees were incorporated in a 'low-high' (non-compliance with the norm at T1 and compliance with the norm at T2) or 'high-low' (compliance with the norm at $\mathrm{T} 1$ and non-compliance with the norm at T2) group. After that, we conducted a 2 (group: 'lowhigh' vs. 'high-low') $\times 2$ (time: T1 vs. T2) ANCOVA with repeated measures on time (RM-ANCOVA) for continuous measures of work-related fatigue and task demands, respectively, and focused on 'group $\times$ time', 'time', and 'group' effects. We controlled for age, gender, education, working overtime, and working irregular hours.

\section{Results}

\section{Descriptive statistics}

The means and standard deviations of study variables at both time points are presented in Table 1. On average, participants were physically active for at least $30 \mathrm{~min}$ on a moderate intensity on 4 days a week (T1: $M=3.98$; T2: $M=4.09$ ). Further inspection of our data revealed that $43.9 \%$ complied with the physical activity norm at $\mathrm{T} 1$ and $45.9 \%$ at $\mathrm{T} 2$. This is lower than a representative sample in the Netherlands, in which $58 \%$ of the population complies with the physical activity norm (Hildebrandt et al. 2013). Most participants reported low levels of workrelated fatigue [at $\mathrm{T} 1,12.4 \%$ reported high (i.e. higher than the cut-off score of 2.2, see Schaufeli and Van Dierendonck 2000) levels of work-related fatigue, and at T2 this was $12.2 \%$ ]. Furthermore, participants displayed relatively high levels of task demands with a mean of 2.44 for $\mathrm{T} 1$ and a mean of 2.42 for $\mathrm{T} 2$, implying that most employees experienced task demands more frequently than 'sometimes'.

Table 1 shows that the core variables under study remain relatively stable between $\mathrm{T} 1$ and $\mathrm{T} 2$, as indicated by $\mathrm{T} 1-\mathrm{T} 2$ correlations of 0.65 (for physical activity), 0.67 (for workrelated fatigue), and 0.68 (for task demands). The pattern of correlations was in the expected direction of our hypotheses, both cross sectional and across-time. A closer examination of compliance with the physical activity norm in relation to high levels of work-related fatigue reveals that at $\mathrm{T} 1,13.8 \%$ of employees who complied reported high work-related fatigue $(\geq 2.2)$, compared to $10.8 \%$ who did not comply. For T2, these figures were 13.0 and $11.4 \%$, respectively. Furthermore, at T1, $50.8 \%$ of employees who complied with the physical activity norm reported high levels of task demands (i.e. a mean score of $\geq 2.5$ was considered as 'high', indicating that demands were more frequently experienced than 'sometimes'), compared to $44.7 \%$ who did not comply. At T2, these figures were 50.3 and $41.9 \%$, respectively.

\section{Across-time relationships}

Fit indices of the four models that were compared to test Hypotheses 1a and $1 \mathrm{~b}$ are presented in Table 2. Model 1 fitted the data well, with significant paths between workrelated fatigue measured at $\mathrm{T} 1$ and at $\mathrm{T} 2(\beta=0.53)$, and between physical activity measured at $\mathrm{T} 1$ and $\mathrm{T} 2$ 


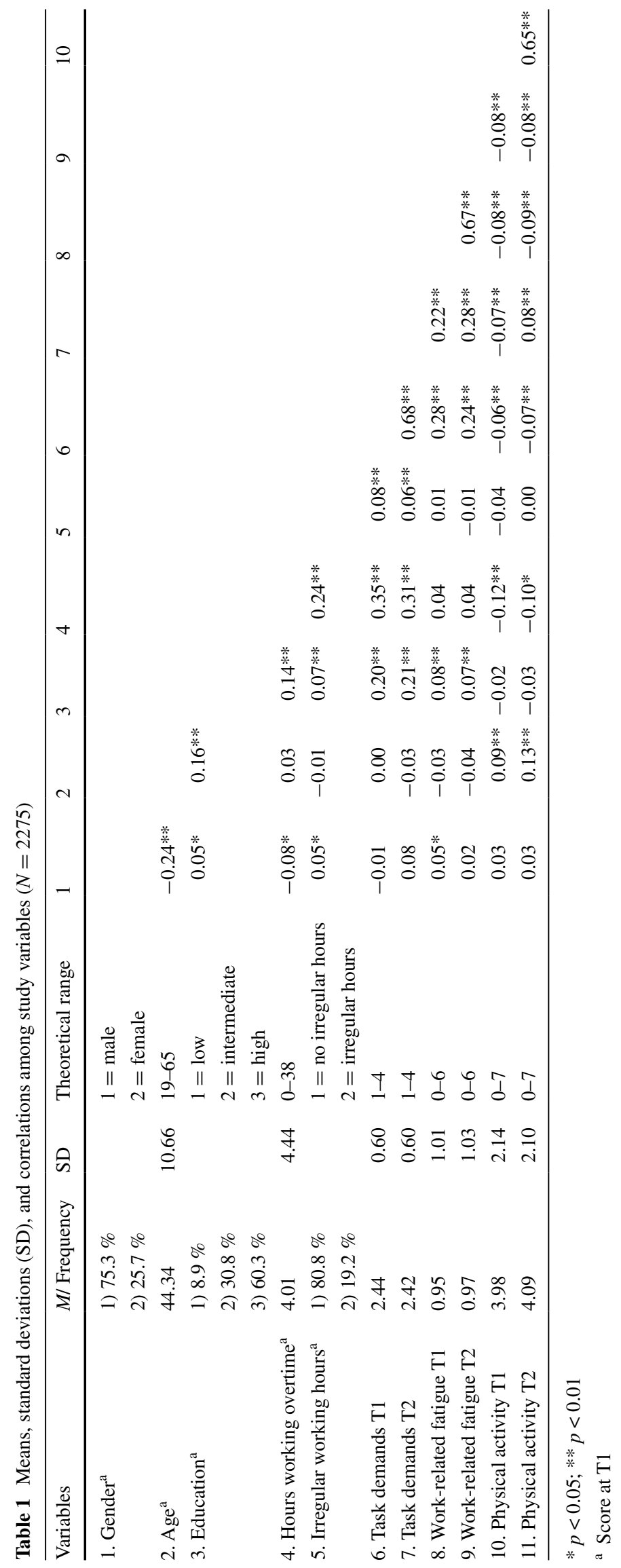


Table 2 Fit indices of structural equation models for the longitudinal associations between physical activity and work-related fatigue, and physical activity and task demands

\begin{tabular}{|c|c|c|c|c|c|c|c|c|c|}
\hline Model & $\chi^{2}$ & $d f$ & NNFI & CFI & AGFI & RMSEA & Model comparison & $\Delta d f$ & $\Delta \chi^{2}$ \\
\hline \multicolumn{10}{|c|}{ Physical activity and work-related fatigue ( $\mathrm{H} 1 \mathrm{a}$ and $\mathrm{H} 1 \mathrm{~b})$} \\
\hline M1 (no causation) & 57.48 & 12 & 0.92 & 0.97 & 0.98 & 0.04 & & & \\
\hline M2 (normal causation) & 49.62 & 11 & 0.93 & 0.98 & 0.98 & 0.04 & M1 versus M2 & 1 & $7.86^{* *}$ \\
\hline M3 (reversed causation) & 39.39 & 11 & 0.95 & 0.98 & 0.98 & 0.03 & M1 versus M3 & 1 & $18.09 * *$ \\
\hline \multirow[t]{2}{*}{ M4 (reciprocal causation) } & 31.65 & 10 & 0.95 & 0.99 & 0.99 & $\mathbf{0 . 0 3}$ & M2 versus M4 & 1 & $17.97 * *$ \\
\hline & & & & & & & M3 versus M4 & 1 & $7.74 * *$ \\
\hline \multicolumn{10}{|c|}{ Physical activity and task demands ( $\mathrm{H} 2 \mathrm{a}$ and $\mathrm{H} 2 \mathrm{~b})$} \\
\hline M1 (no causation) & 58.05 & 12 & 0.93 & 0.98 & 0.98 & 0.04 & & & \\
\hline M2 (normal causation) & 54.93 & 11 & 0.93 & 0.98 & 0.98 & 0.04 & M1 versus M2 & 1 & 3.12 \\
\hline M3 (reversed causation) & 57.12 & 11 & 0.93 & 0.98 & 0.98 & 0.04 & M1 versus M3 & 1 & 0.93 \\
\hline \multirow[t]{2}{*}{ M4 (reciprocal causation) } & 53.99 & 10 & 0.92 & 0.98 & 0.98 & 0.04 & M2 versus M4 & 1 & 0.94 \\
\hline & & & & & & & M3 versus M4 & 1 & 3.13 \\
\hline
\end{tabular}

The models are controlled for gender, age, education, working overtime, and working irregular hours

$* p<0.05 ; * * p<0.01$

Bold indicates best fitting model

$\mathrm{T} 1$

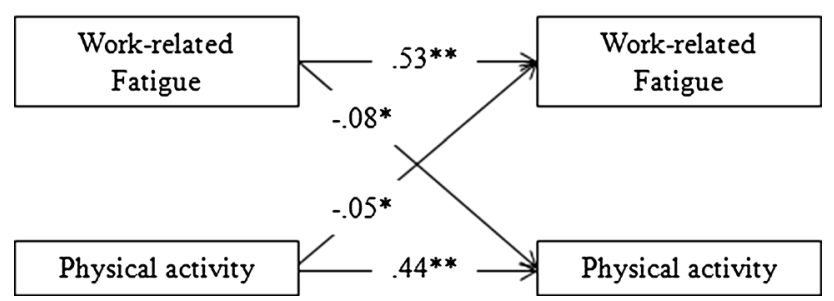

Fig. 1 Reciprocal model (model 4) between work-related fatigue and physical activity (Hypothesis 1a and 1b), controlled for gender, age, education, working overtime, and irregular working hours. Standardized paths $\left(\beta\right.$ 's) are displayed. ${ }^{*} p<0.05 ; * * p<0.01$

( $\beta=0.44$ ). Model 2 also fitted the data well and fitted significantly better than Model 1 (see Table 2 for model comparisons). This model reveals a significant negative association between physical activity $\mathrm{T} 1$ and work-related fatigue T2 ( $\beta=-0.05)$. Also Model 3 fitted the data well and fitted better than Model 1. This model shows a significant negative association between work-related fatigue T1 and physical activity T2 $(\beta=-0.08)$. Table 2 shows that Model 4-including reciprocal associations between physical activity and work-related fatigue- - has an acceptable fit as well and that this model fitted better than both Model 2 and Model 3. Consequently, we chose Model 4 as the best fitting model (see Fig. 1 for a graphical representation). This model shows that physical activity at $\mathrm{T} 1$ is associated with a decrease in work-related fatigue from $\mathrm{T} 1$ to $\mathrm{T} 2$, thus supporting Hypothesis 1a. Further, the model shows that work-related fatigue is associated with a decrease in the level of physical activity from $\mathrm{T} 1$ to $\mathrm{T} 2$, thus supporting
Hypothesis 1b. Additionally, some covariates were significantly related to the constructs of interest at $\mathrm{T} 1$ : working overtime $(\beta=-0.09)$ and age $(\beta=0.05)$ were related to physical activity; and working overtime $(\beta=0.04)$ was related to work-related fatigue.

To test Hypotheses 2a and 2b, again four models were compared. The fit indices and model comparisons of the four models are presented in Table 2. Model 1 fitted the data well, with significant paths from physical activity T1 to physical activity $\mathrm{T} 2(\beta=0.44)$, and from task demands $\mathrm{T} 1$ to task demands $\mathrm{T} 2(\beta=0.56)$. None of the extended models fitted better than Model 1, and therefore, Hypothesis 2a (high levels of task demands are associated with lower levels of physical activity 1 year later) and Hypothesis 2b (higher physical activity levels are associated with lower levels of task demands 1 year later) were not supported.

\section{Subgroup analyses (Hypotheses $3 a$ and $3 b$ )}

The estimated means and standard deviations of workrelated fatigue and task demands for the different physical activity groups are presented in Table 3 . The means and standard deviations of the stable physical activity groups (i.e. compliance at both times and non-compliance at both times) are also depicted in Table 3 to provide a complete picture of what stable and changed physical activity levels mean for work-related fatigue and task demands. As can be seen in Table 3, most participants displayed fairly stable physical activity levels, and relatively few participants changed with regard to compliance with the physical activity norm: $12.1 \%$ of participants showed an upward 
Table 3 Means and standard deviations of work-related fatigue and task demands for the different meaningful physical activity groups, adjusted for age, gender, education, working overtime, and irregular working hours

\begin{tabular}{|c|c|c|c|c|c|c|c|c|c|c|c|}
\hline \multirow[t]{3}{*}{ Physical activity group } & \multirow[t]{3}{*}{$n^{\mathrm{a}}$} & \multicolumn{4}{|c|}{ Work-related fatigue } & \multirow[t]{3}{*}{$D^{\mathrm{d}}$} & \multicolumn{4}{|c|}{ Task demands } & \multirow[t]{3}{*}{$D$} \\
\hline & & \multicolumn{2}{|l|}{$\mathrm{T} 1$} & \multicolumn{2}{|l|}{$\mathrm{T} 2$} & & \multicolumn{2}{|l|}{$\mathrm{T} 1$} & \multicolumn{2}{|l|}{$\mathrm{T} 2$} & \\
\hline & & $M$ & SD & $M$ & SD & & $M$ & SD & $M$ & SD & \\
\hline Low T1-low T2 ${ }^{\mathrm{b}}$ (stable low) & 913 & 1.04 & 0.91 & 1.05 & 0.93 & 0.01 & 2.49 & 0.52 & 2.47 & 0.49 & -0.04 \\
\hline High T1-high $2^{\mathrm{c}}$ (stable high) & 724 & 0.84 & 1.17 & 0.90 & 1.20 & 0.05 & 2.43 & 0.65 & 2.39 & 0.65 & -0.06 \\
\hline Low T1-high T2 (upward change) & 258 & 0.98 & 1.03 & 0.95 & 1.06 & -0.03 & 2.38 & 0.56 & 2.39 & 0.56 & 0.02 \\
\hline High T1-low T2 (downward change) & 225 & 0.90 & 1.02 & 0.88 & 1.05 & -0.02 & 2.39 & 0.56 & 2.42 & 0.56 & 0.05 \\
\hline
\end{tabular}

$* p<0.05 ; * * p<0.01$

a 155 missing values; ' 'Low' = not complying with the physical activity norm (i.e. $<5$ days a week 30 min of moderate-intensity physical activity); ${ }^{\text {c }}$ 'High' = complying with the physical activity norm (i.e. $\geq 5$ days a week 30 min of moderate-intensity physical activity); ${ }^{\text {d }}$ Cohen's $D$ effect size for the mean difference between $\mathrm{T} 1$ and $\mathrm{T} 2$

Table 4 Synthesis of evidence

\begin{tabular}{lll}
\hline Hypotheses & & Longitudinal support \\
\hline H1a & Higher levels of physical activity $\rightarrow$ lower levels of work-related fatigue & + \\
$\mathrm{H} 1 \mathrm{~b}$ & Higher levels of work-related fatigue $\rightarrow$ lower levels of physical activity & + \\
$\mathrm{H} 2 \mathrm{a}$ & Higher levels of task demands $\rightarrow$ lower levels of physical activity & - \\
$\mathrm{H} 2 \mathrm{~b}$ & Higher levels of physical activity $\rightarrow$ lower levels of task demands & - \\
$\mathrm{H} 3 \mathrm{a}$ & Upward physical activity group $\rightarrow$ decrease in work-related fatigue and task demands & - \\
$\mathrm{H} 3 \mathrm{~b}$ & Downward physical activity group $\rightarrow$ increase in work-related fatigue and task demands & - \\
\hline
\end{tabular}

change $(n=258)$ and $10.6 \%$ showed an downward change ( $n=225$ ). The RM-ANCOVA revealed that there was no significant interaction between 'group' and 'time' for work-related fatigue $[F(1,476)=0.74, p=0.391]$ and task demands $[F(1,476)=0.09, p=0.662]$, meaning that changes in levels of work-related fatigue and task demands over time did not differ between the upward and downward physical activity group. The RM-ANCOVA also showed no effect of 'time' on work-related fatigue $[F(1,476)=0.02$, $p=0.893]$ and task demands $[F(1,476)=0.07$, $p=0.793]$, meaning that levels of work-related fatigue and task demands did not change over time. No effect of 'group' was found $[F(1,476)=0.04, p=0.850]$, meaning that the groups did not differ on their mean levels of workrelated fatigue and task demands. All in all, no support was found for Hypotheses $\mathbf{3 a}$ and $\mathbf{3 b}$.

\section{Discussion}

In this study, we examined longitudinal relationships between physical activity, work-related fatigue, and task demands. Our goal was threefold. First, we examined possible bi-directional relationships between physical activity and work-related fatigue (Hypotheses $1 \mathrm{a}$ and $1 \mathrm{~b}$ ). Secondly, we investigated whether employees' task demands and physical activity level mutually influence each other (Hypotheses 2a and 2b). Finally, we addressed the effects of change in employees' adherence with the international physical activity norm in relation to work-related fatigue and task demands (Hypotheses 3a and 3b). Table 4 presents an overview of support levels for this study's hypotheses.

In accordance with previous studies (e.g. Bültmann et al. 2002; Lindwall et al. 2013), we found that higher levels of physical activity were related to lower levels of workrelated fatigue one year later (Hypothesis 1a), although the size of this effect was relatively small. It should be noted, though, that longitudinal effects are always smaller and more difficult to detect than cross-sectional ones (Ford et al. 2014). Also, in this study, we controlled for the level of physical activity and work-related fatigue at T1 in our SEM. As these constructs were rather stable over time (across-time correlations $r=0.65$ for physical activity and $r=0.67$ for work-related fatigue), a large proportion of the variance in physical activity and work-related fatigue was already accounted for by the same indicator measured 1 year earlier. This means that the proportion of variance left to be explained was rather small. The association between physical activity and work-related fatigue was not supported by our subgroup analyses, which showed that a change in compliance with the physical activity norm 
(Hypothesis 3a and 3b) was not related to accompanying changes in work-related fatigue. This discrepancy in findings may be attributed to insufficient contrast between the two physical activity change groups. A closer examination of the data revealed that, in both groups, a notable proportion of participants reported just one or two days change in physical activity (i.e. $42.7 \%$ in the 'upward' change group, and $47.6 \%$ in the 'downward' change group changed one or two days). As a result, it may be difficult to detect intergroup differences in the development of work-related fatigue over time. Thus, within our relatively stable sample, distinguishing between subgroups based on changes in the physical activity norm may not be a sensitive enough method to capture differences in patterns of work-related fatigue over time.

Our results also support the hypothesis that employees' level of work-related fatigue was negatively related to engaging in physical activity (Hypothesis 1b). This could imply that being tired from work is a decisive factor for employees in whether or not to engage in physical activity. This result also implies that even the relatively low levels of work-related fatigue that were experienced by the employees in this study may already interfere with their physical activity levels. Finding reciprocal relations between physical activity and work-related fatigue may point to a downward spiral, in which more work-related fatigue is related to lower physical activity, which in turn relates to even higher levels of work-related fatigue.

Contrary to the few previous studies that addressed this association (Feuerhahn et al. 2014; Fransson et al. 2012; Kouvonen et al. 2013; Payne et al. 2002; Sonnentag and Jelden 2009), we did not find a longitudinal negative association between task demands and physical activity (Hypothesis 2a). Our result may be explained by the fact that task demands especially affect physical activity during leisure time and not during work time (Fransson et al. 2012; Kouvonen et al. 2013), and affect rather activities that are voluntary than compulsory. Unfortunately, due to the measurement of physical activity in this current study, it was unknown whether employees' physical activity entailed (voluntary) sport activities during leisure time, or that it was part of compulsory activities during daily life (e.g. at work or during household chores). The latter types of activities are often obligatory and part of daily routines and will thus not be easily skipped, while (voluntary) sports activities during leisure time may be more easily omitted if one's resources are depleted due to high task demands.

Also, no support was found for the idea that higher levels of physical activity are related to lower levels of task demands over time (Hypothesis 2b). Similarly, the upward and downward physical activity groups did not show changes in task demands over time (Hypotheses $3 a$ and $3 b$ ). An explanation for these findings may be that task demands are partly 'inherent' to the job and thus cannot easily be changed. It may also be that changes in physiological, psychological, and cognitive health that can develop within a one-year time lag are too small to induce a response shift in the evaluation of task demands. Furthermore, it may be that not all types of physical activity impact task demands. For instance, one can imagine that sport activities result in mastery experiences (Craft 2005), which reduce perceived task demands, due to an increase in self-efficacy in the work domain. For other physical activities, such as physical household activities, this association may not be found, because these may not be associated with mastery experiences. Unfortunately, again referring to the measurement of physical activity in this current study, we cannot distinguish between these different types of physical activity.

\section{Limitations and suggestions for future research}

There are seven issues concerning the current study that deserve attention. First, we exclusively relied on self-report measures in the present study. Some consider this to be a limitation, because it would result in an overestimation of the associations among variables due to common method variance. Based on his study of the potential problem of common method variance, Spector (2006) nonetheless concluded that 'the popular position suggesting that common method variance automatically affects variables measured with the same method is a distortion and oversimplification of the true state of affairs' (p. 221). Besides, internal states, such as work-related fatigue, can best be mapped by means of reports by those who are involved in these experiences. This notwithstanding, it would be valuable for future studies to combine self-report measures of physical activity with more objective methods, such as accelerometers or actigraphy (Prince et al. 2008).

Second - and related to the first issue-the self-report measurement of physical activity deserves attention. In general, people often over- or underestimate their true physical activity level, for instance due to recall bias or social desirability (Prince et al. 2008). Therefore, it is likely that self-report measures in this current study do not precisely reflect employees' actual physical activity levels. In addition, participants in the current study were asked 'on how many days a week they were physically active for at least $30 \mathrm{~min}$ at a moderate intensity'. As a result, the exact total duration and frequency of employees' physical activity were unknown (e.g. when someone answers ' 3 days', it could be exactly $90 \mathrm{~min}$, but also more than this amount). Also, the exact intensity of the physical activity was not known. We only knew that the physical activity was at least of moderate intensity. Intensity is important, because it may affect work-related fatigue in different 
ways. For instance, it has been found that physical activity at a high intensity heightens someone's fatigue and may even lead to exhaustion (Loy et al. 2013), whereas low (Puetz et al. 2008)-to-moderate intensity (Salmon 2001) physical activity levels are related to lower fatigue. Furthermore, the type of physical activity was unknown (e.g. non-aerobic training, physical activity as part of daily life, or as sport activity). Different types of physical activity could have distinct effects on work-related fatigue. There are reasons to believe that physical activity as part of household chores is not beneficial for work-related fatigue, whereas sport activities are (Demerouti et al. 2009). Based on these considerations, it is important that future studies measure the intensity (i.e. low, moderate, high), duration, frequency, and type (i.e. aerobic or non-aerobic, and during leisure time or part of daily life) of physical activity (e.g. Aadahl and Jørgensen 2003) and investigate which may benefit work-related fatigue most.

Third, also relating to the specific measurement of physical activity in the current study, we could not unravel whether employees' physical activity was performed during leisure or work time. Therefore, we chose to not include employees with potentially unhealthy physical demanding work to prevent that the association between physical activity and work-related fatigue was confounded by such unhealthy physical activity. This is unfortunate, because it has been shown that employees engaging in physical demanding work can also benefit from leisure time physical activity with regard to their health (e.g. Holtermann et al. 2013). Future research could further disentangle the associations between physical activity, work-related fatigue, and task demands by explicitly examining employees with physically demanding work.

A fourth issue that needs attention is that there was relatively small across-time variation in the variables included in this study. This is reflected in the relatively high testretest correlations over time (ranging from $r=0.65$ to 0.69 ) and stable mean scores (see Table 1). This would imply that a longer time interval should be covered in order to investigate the impact of change in physical activity on work-related fatigue and task demands. Furthermore, including more time points is preferable to detect the 'true' time lag underlying the observed associations (Taris and Kompier 2003).

Fifth, as our sample consisted of relatively healthy workers, it may well be possible that there was a restriction of range leading to an underestimation of the true relationships found in this current study. For instance, in accordance with previous studies that demonstrated negative associations between physical activity on clinical levels of work-related fatigue (Bültmann et al. 2002; Gerber et al. 2013), the effect of physical activity on work-related fatigue found in this study might be an underestimation of the true (causal) effect. Further research is needed to investigate this.

Sixth, our selection criteria of participants resulted in a relatively small proportion of the original sample $(28.8 \%)$. Although our choice of selecting full-time ( $\geq 36$ working hours) employees was based on theoretical grounds, it would be interesting to see whether the relations found in our study also exist if we would have used other working hour limits. We therefore reanalysed our data, including all employees, irrespective of their working hours. The results of these analyses (based on all employees, irrespective of their working hours) revealed a comparable pattern of results, ${ }^{1}$ which underlines the robustness of our findings.

Finally, we were not able to draw firm conclusions regarding causality with respect to the observed longitudinal associations, because we could not eliminate the influence of potentially relevant third variables (Taris and Kompier 2003). To get further insight into the causal associations between physical activity and work-related fatigue and task demands, further research is needed in the form of well-designed randomized controlled trials, for instance targeting physical activity levels of employees with (clinical levels of) work-related fatigue (Proper et al. 2002).

\section{Theoretical and practical implications}

We believe our study contributes to previous research on physical activity and employee health both theoretically and practically. To our knowledge, we were among the first to longitudinally investigate 'bi-directional' relationships between physical activity and work-related fatigue, and physical activity and task demands. By doing so, we were able to provide a basic understanding of how physical activity is related to work-related mental health and to work characteristics. Furthermore, we tried to obtain more thorough insight into these relationships by investigating how work-related fatigue and task demands develop as a function of different (i.e. changed) meaningful physical activity patterns over time, based on employees' compliance with the international physical activity standards (World Health Organization [WHO] 2010). Even though our core variables under study proved to be rather stable during the one-year time lag of this study, and even though physical activity could have been measured more thoroughly, we were able to demonstrate that an increase in physical activity was related to a decrease in work-related fatigue over time. This highlights the importance of physical activity for the protection of employee health and well-being. But, we also demonstrated that fatigued workers, who would benefit

\footnotetext{
${ }_{1}^{1}$ Results of these analyses can be requested from the first author.
} 
most from physical activity, engaged less in this type of activity. Therefore, it seems important to pay attention how to motivate fatigued employees to engage in regular physical activity. For instance, evidence shows that learning to focus on the ending of a physical activity session, instead on the often unpleasant beginning of physical activity, is a potential to increase people's physical activity level (Ruby et al. 2011). In addition, the finding that changes in adherence to international standards of physical activity were not related to accompanying changes in work-related fatigue, indicates that relying on changes in compliance with this standard may not the most suitable way to examine changes in work-related fatigue. In this respect, it is interesting to note that the dichotomous approach of the physical activity norm is currently under discussion. Although it has been shown that the physical activity norm is certainly meaningful for (mental) health (Haskell et al. 2007), it has been argued that a slight increase in physical activity for people who are inactive could already result in health benefits (De Sauto Barreto 2015; Sparling et al. 2015). Thus, a dose-response approach (i.e. small incremental increases in daily physical activity) may be more appropriate than a 'threshold approach' (i.e. compliance or non-compliance) for promoting physical activity.

From a practical point of view, current findings suggest that it is valuable for employees to be physically active, in leisure time as well as during work time (Commissaris et al. 2008). Based on the demonstrated beneficial effects of physical activity, the employer can be encouraged to promote physical activity at the workplace by stimulating physically active transportation to work, designing 'active' workplaces or offering physical activity programs at work (Conn et al. 2009). Furthermore, employees should strive to make physical activity part of their daily routine, even when fatigued.

Conflict of interest The authors declare that they have no conflict of interest.

Open Access This article is distributed under the terms of the Creative Commons Attribution 4.0 International License (http://creativecommons.org/licenses/by/4.0/), which permits unrestricted use, distribution, and reproduction in any medium, provided you give appropriate credit to the original author(s) and the source, provide a link to the Creative Commons license, and indicate if changes were made.

\section{References}

Aadahl M, Jørgensen T (2003) Validation of a new self-report instrument for measuring physical activity. Med Sci Sports Exerc 35:1196-1202. doi:10.1249/01.MSS.0000074446.02192.14

Ahola K, Pulkki-Råback L, Kouvonen A, Rossi H, Aromaa A, Lönnqvist J (2012) Burnout and behavior-related health risk factors: results from the population-based Finnish health 2000 study. J Occup Environ Med 54:17-22. doi:10.1097/JOM.0b013e31823ea9d9
Ament W, Verkerke GJ (2009) Exercise and fatigue. Sports Med 39:389-422. doi:10.2165/00007256-200939050-00005

Arvidson E, Borjesson M, Ahlborg G, Lindegard A, Jonsdottir IH (2013) The level of leisure time physical activity is associated with work ability-a cross sectional and prospective study of health care workers. BMC Public Health 2013(13):855. doi:10.1186/1471-2458-13-855

Bentler PM, Bonnett DG (1980) Significance tests and goodness of fit in the analysis of covariance structures. Psychol Bull 88:588606. doi:10.1037/0033-2909.88.3.588

Bernaards CM, Jans MP, Van den Heuvel SG, Hendriksen IJ, Houtman IL, Bongers PM (2006) Can strenuous leisure time physical activity prevent psychological complaints in a working population? Occup Environ Med 63:10-16. doi:10.1136/ oem.2004.017541

Brosschot JF, Gerin W, Thayer JF (2006) The perseverative cognition hypothesis: a review of worry, prolonged stress-related physiological activation, and health. J Psychosom Res 60:113-124. doi:10.1016/j.jpsychores.2005.06.074

Bültmann U, Kant I, Kasl SV, Schroër KA, Swaen GM, Van den Brandt PA (2002) Lifestyle factors as risk factors for fatigue and psychological distress in the working population: prospective results from the Maastricht Cohort Study. J Occup Environ Med 44:116-124. doi:10.1097/00043764-200202000-00006

Campbell A, Hausenblas HA (2009) Effects of exercise interventions on body image: a meta-analysis. J Health Psychol 14:780-793. doi:10.1177/1359105309338977

Carson RL, Baumgartner JJ, Matthews RA, Tsouloupas CN (2010) Emotional exhaustion, absenteeism, and turnover intentions in childcare teachers: examining the impact of physical activity behaviors. J Health Psychol 15:905-914. doi: $10.1177 / 1359105309360697$

Colcombe S, Kramer AF (2003) Fitness effects on the cognitive function of older adults: a meta-analytic study. Psychol Sci 14:125130. doi:10.1111/1467-9280.t01-1-01430

Commissaris DACM, Douwes M, Schoenmaker N, de Korte EM (2008). Recommendations for sufficient physical activity at work. http://tools.nisb.nl/beleidsinstrumenten/bravo-kompas/ bewegen/tno_kvl_richtlijnen_voldoende_bewegen_op_werk.pdf

Conn V (2010) Depressive symptom outcomes of physical activity interventions: meta-analysis findings. Ann Behav Med 39:128138. doi:10.1007/s12160-010-9172-x

Conn VS, Hafdahl AR, Cooper PS, Brown LM, Lusk SL (2009) Meta-analysis of workplace physical activity interventions. Am J Prev Med 37:330-339. doi:10.1016/j.amepre.2009.06.008

Cooney GM, Dwan K, Greig CA, Lawlor DA, Rimer J, Waugh FR, McMurdo M, Mead GE (2013) Exercise for depression. Cochrane database systematic review 19: CD004366. doi: 10.1002/14651858.CD004366.pub6

Craft LL (2005) Exercise and clinical depression: examining two psychological mechanisms. Psychol Sport Exerc 6:151-171. doi:10.1016/j.psychsport.2003.11.003

Cropley M, Purvis LJ (2003) Job strain and rumination about work issues during leisure time: a diary study. Eur J Work Organ Psychol 12:195-207. doi:10.1080/13594320344000093

De Lange AH, Taris TW, Kompier MAJ, Houtman ILD, Bongers PM (2002) Effects of stable and changing demand-control histories on worker health. Scand J Work Environ Health 28:94-108. doi:10.5271/sjweh.653

De Lange AH, Taris TW, Kompier MAJ, Houtman ILD, Bongers PM (2003) The very best of the millennium: longitudinal research and the demands-control-(support) model. J Occup Health Psychol 8:282-305. doi:10.1037/1076-8998.8.4.282

De Sauto Barreto P (2015) Global health agenda on non-communicable diseases: has WHO set a smart goal for physical activity? BMJ 350:h23. doi:10.1136/bmj.h23 
Demerouti E, Bakker AB, Geurts SAE, Taris TW (2009) Daily recovery from work-related effort during non-work time. Res Occup Stress Well Being 7:85-123. doi:10.1108/S1479-3555(2009)0000007006

Dishman RK, O'Connor PJ (2009) Lessons in exercise neurobiology: the case of endorphins. Ment Health Phys Act 2:4-9. doi:10.1016/j.mhpa.2009.01.002

Dishman RK et al (2006) Neurobiology of exercise. Obesity 14:345356. doi: $10.1038 /$ oby. 2006.46

Eurofound (2012) Fifth European working conditions survey [EWCS]. Publications Office of the European Union, Luxembourg

Feuerhahn N, Sonnentag S, Woll A (2014) Exercise after work, psychological mediators, and affect: a day-level study. Eur J Work Organ Psychol 23:62-79. doi:10.1080/1359432X.2012.709965

Ford MT, Matthews RA, Wooldridge JD, Mishra V, Kakar UM, Strahan SR (2014) How do occupational stressor-strain effects vary with time? A review and meta-analysis of the relevance of time lags in longitudinal studies. Work and Stress 28(9):30. doi:10.10 80/02678373.2013.877096

Fransson EI, Heikkilä K, Nyberg ST, Zins M, Westerlund H, Westerholm P et al (2012) Job strain as a risk factor for leisure-time physical inactivity: an individual participant meta-analysis of up to 170,000 men and women. Am J Epidemiol 176:1078-1089. doi:10.1093/aje/kws336

Gerber M, Brand S, Elliot C, Holsboer-Trachsler E, Pühse U, Beck J (2013) Aerobic exercise training and burnout: a pilot study with male participants suffering from burnout. BMC Res Notes 6:78. doi:10.1186/1756-0500-6-78

Gorter RC, Eijkman MAJ, Hoogstraten J (2000) Burnout and health among Dutch dentists. Eur J Oral Sci 108:261-267. doi:10.1034/j.1600-0722.2000.108004261.x

Haskell WL, Lee IM, Pate RR, Powell KE, Blair SN, Franklin BA, Macera CA, Heath GW, Thompson PD, Bauman A (2007) Physical activity and public health: updated recommendation for adults from the American College of Sports Medicine and the American Heart Association. Med Sci Sports Exerc 39:14231434. doi:10.1161/CIRCULATION.107.185649

Hildebrandt VH, Chorus AMJ, Stubbe JH (2010) Trendrapport Bewegen en Gezondheid (trend report physical activity and health). TNO Kwaliteit van Leven (Quality of Life): Leiden (the Netherlands)

Hildebrandt VH, Bernaards C, Chorus A, Hofstetter H (2013) Trendrapport Bewegen en Gezondheid 2000-2011 (trend report physical activity and health from 2000 to 2011). TNO, Leiden (the Netherlands)

Hockey RV (2013) The psychology of fatigue: work, effort and control. Cambridge University Press, Cambridge

Holtermann A, Marott JL, Gyntelberg F, Søgaard K, Suadicani P, Mortensen OS, Prescott E, Schnohr P (2013) Does the benefit on survival from leisure time physical activity depend on physical activity at work? A prospective cohort study. PLoS ONE 8:e54548. doi:10.1371/journal.pone.0054548

Houtman I (1995) Reliability and validity of the Dutch version of the Karasek Job Content Questionnaire. NIOSH/APA conference on stress, work and health. APA, Washington (DC)

Jonsdottir IH, Rödjer L, Hadzibajramovic E, Börjesson M, Ahlborg $G$ (2010) A prospective study of leisure-time physical activity and mental health in Swedish health care workers and social insurance officers. Prev Med 5:373-377. doi:10.1016/j. ypmed.2010.07.019

Jöreskog K, Sörbom D (1993) Lisrel 8: structrual equation modeling with the SIMPLIS command language. Scientific Software International, Lincolnwood

Karasek RA (1979) Job demands, job decision latitude, and mental strain: implications for job redesign. Adm Sci Quart 24:285-308. doi: $10.2307 / 2392498$
Karasek R, Brisson C, Kawakami N, Houtman I, Bongers P, Amick B (1998) The job content questionnaire (JCQ): an instrument for internationally comparative assessments of psychosocial job characteristics. J Occup Health Psychol 3:322-355. doi:10.1037/1076-8998.3.4.322

Kompier M (2003) Job design and well-being. In: Schabracq M, Winnubst J, Cooper CL (eds) Handbook of work and health psychology. Wiley, Chichester (UK), pp 429-454

Koppes LLJ, De Vroome EMM, Van den Bossche SNJ (2010) The Netherlands working conditions cohort study. TNO, Hoofddorp

Kouvonen A, Vahtera J, Oksanen T, Pentti J, Väänänen AKP, Heponiemi T, Salo P, Virtanen M, Kivimäki M (2013) Chronic workplace stress and insufficient physical activity: a cohort study. Occup Environ Med 70:3-8. doi:10.1136/oemed-2012-100808

Leith LM (1994) Foundations of exercise and mental health. Fitness Information Technology, Morgantown

Lindwall M, Gerber M, Jonsdottir IH, Börjesson M, Ahlborg G (2013) The relationships of change in physical activity with change in depression, anxiety, and burnout: a longitudinal study of Swedish healthcare workers. Health Psychol (epub ahead of print). doi: 10.1037/a0034402

Loy BD, O'Connor PJ, Dishman RK (2013) The effect of a single bout of exercise on energy and fatigue states: a systematic review and meta-analysis. Fatigue: biomed. Fatigue 4:223-242. doi:10.1 080/21641846.2013.843266

Marsh HW, Hau K, Wen Z (2004) In search of golden rules: comment on hypothesis-testing approaches to setting cutoff values for fit indexes and dangers in overgeneralizing $\mathrm{Hu}$ and Bentler's (1999) findings. Struct Equ Model 11:320-341. doi:10.1207/ s15328007sem1103_2

Maslach C, Schaufeli WB, Leiter MP (2001) Job Burnout. Annu Rev Psychol 52:397-422. doi:10.1146/annurev.psych.52.1.397

Milczarek M, Schneider E, González ER (2009) OSH in figures: stress at work-facts and figures. Luxembourg: European agency for safety and health at work. https://osha.europa.eu/en/publications/reports/TE-81-08-478-ENC_OSH_in_figures_stress_at_ work. Accessed 1 Juni 2014

Mollart L, Skinner VM, Newing C, Foureur M (2013) Factors that may influence midwives work-related stress and burnout. Women Birth 26:26-32. doi:10.1016/j.wombi.2011.08.002

Nägel IJ, Sonnentag S (2013) Exercise and sleep predict personal resources in employees' daily lives. Health Well-being 5:348368. doi:10.1111/aphw.12014

Niedhammer I, Sultan-Taieb H, Chastang JF, Vermeylen G, ParentThirion A (2014) Fractions of cardiovascular diseases and mental disorders attributable to psychosocial work factors in 31 countries in Europe. Int Arch Occup Environ Health 87:403-411. doi:10.1007/s00420-013-0879-4

Payne N, Jones F, Harris P (2002) The impact of working life on health behavior: the effect of job strain on the cognitive predictors of exercise. J Occup Health Psychol 7:342-353

Prince SA, Adamo KB, Hamel ME, Hardt J, Connor-Gorber S, Tremblay M (2008) A comparison of direct versus self-report measures for assessing physical activity in adults: a systematic review. Int J Beh Nutr Physic Activ 5:56. doi:10.1186/1479-5868-5-56

Proper KI, Staal BJ, Hildebrandt VH, Van der Beek AJ, Mechelen W (2002) Effectiveness of physical activity programs at worksites with respect to work-related outcomes. Scan J Work Environ Health 28:75-84. doi:10.5271/sjweh.651

Proper KI, Koning M, Van der Beek AJ, Hildebrandt VH, Bosscher RJ, Van Mechelen W (2003) The effectiveness of worksite physical activity programs on physical activity, physical fitness, and health. Clin J Sport Med 13:106-117

Puetz TW, Herring MP (2013) Physical activity and feelings of fatigue. In: Ekkekakis P (ed) Physical activity and mental health. Routledge, Abingdon, pp 422-440 
Puetz TW, Flowers SS, O'Connor PJ (2008) A randomized controlled trial of the effect of aerobic exercise training on feelings of energy and fatigue in sedentary young adults with persistent fatigue. Psychother Psychosom 77:167-174. doi:10.1159/000116610

Rook JW, Zijlstra FRH (2006) The contribution of various types of activities to recovery. Eur J Work Organ Psychol 15:218-240. doi:10.1080/13594320500513962

Ruby MB, Dunn EW, Perrino A, Gillis R, Viel S (2011) The invisible benefits of exercise. Health Psychol 30:67-74. doi:10.1037/ a0021859

Salmon P (2001) Effects of physical exercise on anxiety, depression, and sensitivity to stress: an unifying theory. Clin Psychol Rev 21:33-61. doi:10.1016/S0272-7358(99)00032-X

Schaufeli WB, Van Dierendonck D (2000) UBOS Utrecht Burnout Schaal Handleiding. Swets and Zeitlinger BV, Lisse (The Netherlands)

Sonnentag S (2012) Psychological detachment from work during leisure time: the benefits of mentally disengaging from work. Curr Dir Psychol Sci 22:114-118. doi:10.1177/0963721411434979

Sonnentag S, Jelden S (2009) Job stressors and the pursuit of sport activities: a day-level perspective. J Occup Health Psychol 14:165-181. doi:10.1037/a0014953

Sothman MS, Buckworth J, Claytor RP, Cox RH, White-Welkley JE, Dishman RK (1996) Exercise training and the cross-stressor adaptation hypothesis. Exerc Sport Sci Rev 24:267-287. doi:10.1249/00003677-199600240-00011

Spalding TW, Lyon LA, Steel DH, Hatfield BD (2004) Aerobic exercise training and cardiovascular reactivity to psychological stress in sedentary young normotensive men and women. Psychophysiol 41:552-562. doi:10.1111/j.1469-8986.2004.00184.x

Sparling PB, Howard BJ, Dunstan DW, Owen N (2015) Recommendations for physical activity in older adults. BMJ 350:h100. doi:10.1136/bmj.h100
Spector PE (2006) Method variance in organizational research. Truth or urban legend? Organ Res Method 9:221-232. doi: $10.1177 / 1094428105284955$

Taris T, Kompier M (2003) Challenges of longitudinal designs in occupational health psychology. Scand J Work Environ Health 29:1-4. doi:10.5271/sjweh.697-\&gt

Tian Q, Smith JC (2011) Attentional bias to emotional stimuli is altered during moderate but not high intensity exercise. Emotion 11:1415-1424. doi:10.1037/a0023568

Trinkoff AM, Storr CL, Lipscomb JA (2001) Physically demanding work and inadequate sleep, pain medication use, and absenteeism in registered nurses. J Occup Environ Med 43:355-363. doi:10.1097/00043764-200104000-00012

Tsai HH, Yeh CY, Su CT, Chen CJ, Peng SM, Chen RY (2013) The effects of exercise program on burnout and metabolic syndrome components in banking and insurance workers. Ind Health 51:336-446. doi:10.2486/indhealth.2012-0188

Van Hooff MLM, Geurts SAE, Taris TW, Kompier MAJ, Dikkers JSE, Houtman ILD, Van den Heuvel FMM (2005) Disentangling the causal relationships between work-home interference and employee health. Scand J Work Environ Health 31:15-29. doi:10.5271/sjweh.844

Van Rhenen W, Blonk RWB, Van Der Klink JJL, Van Dijk F, Schaufeli WB (2005) The effect of a cognitive and a physical stress-reducing programme on psychological problems. Int Arch Occup Environ Health 78:139-148. doi:10.1007/s00420-004-0566-6

Wipfli B, Ramirez E (2013) Stress reactivity in humans and animals: two meta-analyses. Int J Exerc Sci 6:144-156

World Health Organization [WHO] (2010) Global recommendations on physical activity for health. WHO press, Geneva 